\title{
Indios coloniales de Antioquia y el valle del río Cauca: un balance historiográfico [1978-2020]
}

Resumen: Este trabajo revisa los textos sobre los pueblos indígenas del periodo colonial en el valle del río Cauca y la gobernación de Antioquia. Se ubican los temas, problemas, metodologías, periodizaciones, espacialidades y abordajes utilizados en la comprensión de agentes importantes en la historiografía, así como de sus tendencias. Es el fruto de una revisión bibliográfica que permite abordar los cambios en las preguntas e intereses investigativos. De la misma forma, se pueden reconocer la vitalidad del tema, los diálogos y las apropiaciones de los aportes dados por autores y trabajos producidos respecto a los mismos actores en otros espacios.

Palabras clave: indígenas, etnohistoria, colonia, balance historiográfico, historia regional.

\section{Colonial Indians of Antioquia and the Cauca River Valley: a historiographic review [1978-2020]}

Abstract: This overview reviews the works on indigenous peoples in the colonial period in the Cauca river valley and the Antioquia government. Topics, problems, methodologies, periodizations, spatialities, and approaches used to understand essential historiography agents and their tendencies are identified. It results from a bibliographic review and allows addressing changes in the questions and research interests. In the same way, the vitality of the theme, the dialogues, and the appropriations of the contributions given by authors and works produced regarding the same actors in other spaces can be recognized.

Keywords: indigenous, ethnohistory, colonial period, historiographic review, regional history.

\section{Índios coloniais de Antioquia e do Vale do Rio Cauca: um balanço historiográfico [1978-2020]}

Resumo: Este trabalho analisa os textos sobre os povos indígenas do período colonial no vale do rio Cauca e no governo de Antioquia. Localizam-se temas, problemas, metodologias, periodizações, espacialidades e abordagens utilizadas na compreensão de agentes importantes na historiografia, bem como suas tendências. É fruto de uma revisão bibliográfica que permite abordar mudanças em questões e em interesses de pesquisa. Da mesma forma, pode-se reconhecer a vitalidade do tema, os diálogos e as apropriações de contribuições dadas por autores e obras produzidas sobre os mesmos atores em outros espaços.

Palavras-chave: indígenas, etno-história, período colonial, revisão historiográfica, história regional.

Cómo citar este artículo: Héctor Cuevas Arenas, "Indios coloniales de Antioquia y el valle del río Cauca: un balance historiográfico [1978-2020]”, Trashumante. Revista Americana de Historia Social 19 [2022]: 232-253.

DOI: 10.17533/udea.trahs.n19a11

Fecha de recepción: 26 de noviembre de 2020

Fecha de aprobación: 26 de agosto de 2021

Héctor Cuevas Arenas: Doctor en Historia de los Andes por la Facultad Latinoamericana de Ciencias Sociales [FLACSO], sede Ecuador. Docente e investigador del Grupo de investigación en Ciencias Sociales y Humanas [GISOHA] de la Universidad Santiago de Cali. ORCID: 0000-0002-6550-2760.

Correo electrónico: hector.cuevas00@usc.edu.co 


\title{
Indios coloniales de Antioquia y el valle del río Cauca: un balance historiográfico [1978-2020]
}

\author{
Héctor Cuevas Arenas
}

\section{Introducción}

$\mathrm{L}$ a categoría social de "indio" o "indígena" es diacrónica, contextual y flexible, e indagar por ella es reconstruir la diversidad que ha tenido en la heterogeneidad de la monarquía española y los posteriores periodos republicanos. Entender sus avatares, procesos y dinámicas ha sido una constante preocupación entre los historiadores ocupados del periodo "colonial", y una de las entradas para comprender su complejidad e importancia es la historia regional.

La revisión de la historiografia producida sobre los indios implica reconocer las orientaciones académicas, epistemologías y problemáticas que han enriquecido la comprensión de unos actores que siguen vigentes. La historia de la práctica historiográfica y etnohistórica al respecto permite establecer balances, horizontes y tendencias a través de un trabajo de clasificación para entender recorridos, preguntas y respuestas que han alimentado debates académicos y de la opinión pública. Además, un ejercicio de estos es una puerta de entrada para futuros investigadores del tema o de los espacios involucrados en tal escrutinio. Este texto se inserta en tal dinámica y su objetivo es presentar un balance historiográfico de la bibliografía pertinente a los pueblos indios del valle del río Cauca, en la gobernación de Popayán, y de gran parte de la provincia de Antioquia en el periodo de conquista y el que se puede denominar “colonial”. El interés del artículo está en reconstruir la pluralidad de visiones que han analizado a los agentes sociales, lo cual demuestra su presencia como tema de estudio. De la misma manera, se describirán los lazos con otras ramas del conocimiento social y humanístico que generan vitalidad y renovación en la comprensión del actuar de los indios. Esto se hará sin calificativos anacrónicos o desacreditaciones sobre cada momento y con el interés de recuperar

* Artículo producido en el marco del proyecto "Divergencias y convergencias en las expresiones de cultura política: los casos judiciales de los indios en el valle del río Cauca y la gobernación de Antioquia (1680-1750)". Código 562-621119-423. Proyecto financiado por la convocatoria 07-2019: Fortalecimiento de la investigación en comunicación y publicidad de la Universidad Santiago de Cali. 
la trayectoria de los actores en el escenario de la historia regional, para remarcar así su presencia e importancia, sin afanes totalizadores.

Para la investigación, se escogió una región geográfica específica de la gobernación de Popayán: el valle del río Cauca, el cual abarcaba a las ciudades de Cali, Buga, Toro, Caloto y Cartago, junto a gran parte de la gobernación de Antioquia, específicamente las ciudades de Cáceres, Zaragoza y Remedios, con las villas de Medellín y, a partir de 1756, la de Arma. Una justificación para escoger la historiografia sobre los indios de dos regiones distintas se explica porque, en términos de presencia española, pueden ser comparables cinco ciudades de un espacio a las cuatro ciudades con cuatro villas sufragáneas en el otro. Para el siglo XVIII, solo Antioquia, Medellín, Arma (Rionegro) y Remedios tenían pueblos de indios, lo que equilibra un tanto el asunto. Sin embargo, esta elección se tomó debido a que los grupos que encontraron los españoles, y que después se transformaron con ellos y con otras poblaciones de ascendencia prehispánica y africana, tuvieron trayectorias análogas de cambios culturales, territoriales y políticos dentro de lo colonial. Fueron pueblos que se desplazaron de sus espacios de origen, formaban pequeñas encomiendas, sus unidades políticas se disolvieron, se volvieron ladinos (hispanoparlantes y católicos) y se identificaron en menos de un siglo de contacto con lo español. No conservaron identidades étnicas diferenciadas ni lenguas para mediados del siglo XVII por su heterogénea formación. Cabe anotar que no se escogió bibliografía sobre los pueblos indios del cañón medio del río Cauca en la antigua ciudad de Anserma, que sí conservaron lenguas y tradiciones diferenciadas a lo hispánico, por lo que escaparían a la anterior caracterización que sirve de parámetro comparativo. Tampoco, por los anteriores motivos, se tuvieron en cuenta los indígenas del pueblo de Cañasgordas, el cual fue fundado en 1776 con grupos parcialmente sometidos de la vertiente del oeste de la cordillera occidental.

Estas dinámicas han sido recogidas por diversos investigadores que han tamizado con diferentes ópticas a estos agentes que pasaron de lo étnico a lo sociojurídico o, como se denomina en los últimos años, a la categoría de calidad social. ${ }^{1}$ Los indios han sido revisados y reflexionados dentro de la práctica historiográfica profesional hecha en las universidades, que en estos casos empezaron desde $1978 .{ }^{2}$ Como delimitación, no se escogieron trabajos elaborados por fuera de las universidades ni de su rigor científico y disciplinar, debido a que se trata de sintetizar los desarrollos interdisciplinares de la historia y la antropología. Inicialmente, las investigaciones se sustentaron en modelos económicos y sociales estructurales y funcionalistas, para complementarse en la última década con preguntas a partir de la cultura política, la microhistoria y los cambios en las prácticas argumentados

1. Joanne Rappaport, El mestizo evanescente. Configuración de la diferencia en el Nuevo Reino de Granada (Bogotá: Editorial Universidad del Rosario, 2018) 255-282.

2. Juan Friede, Los quimbayas bajo la dominación española. Estudio documental 1539-1810 (Bogotá: Carlos Valencia Editores, 1978); Margarita González Pacciotti, "El resguardo minero de Antioquia”, Anuario Colombiano de Historia Social y de la Cultura 9 (1979): 17-37. 
con la antropología cultural y social. En este balance, se recogen textos ubicados por fuera de narrativas propias de historias de bronces, regionalistas y nacionalistas.

Con el objetivo de desarrollar esta tipología, el artículo aborda, por una parte, los contextos en los que se desenvolvieron los indios de ambas regiones que han reconstruido los historiadores, para pasar a la descripción de las tendencias historiográficas (socioeconómicas, etnohistorias, historia cultural y de la cultura política), en las que se pueden agrupar los trabajos revisados. También se detallan problemas estudiados, aportes, enfoques, agencialidad, espacialidades y periodizaciones, junto a caracterizaciones sobre lo indígena y su relación con la monarquía, al darle esta a los indios su condición jurídica en el marco de un cuerpo social y político. Finalmente, se ubican las conclusiones, donde se establecen recorridos y expectativas respecto a los temas, actores y problemáticas tratadas.

\section{Dos contextos regionales}

Los casos regionales aquí estudiados divergen respecto de los espacios centrales de la monarquía española, debido a que no están amparados en generalizaciones geográficas y culturales, a la manera mesoamericana o andina.Tampoco estuvieron incluidos en unidades políticas supraétnicas anteriores a los españoles. Las sociedades prehispánicas de estas regiones se ubicaban dentro de lo que se ha descrito como cacicazgos simples o compuestos, ${ }^{3}$ con un rango territorial que podía abarcar una comunidad aldeana, una cuenca hidrográfica o que, en un nivel mayor, estaban articulados mediante jefaturas étnicas principales con caciques secundarios. Cada uno de estos cacicazgos contaba con jerarquías sociales sustentadas en variadas formas de apropiación y redistribución de los excedentes de la producción comunal por parte de sus elites.

En varios casos, la incorporación de estas sociedades a la monarquía española fue un proceso discontinuo y problemático, que conservó algunas comarcas, como, por ejemplo, las vertientes del océano Pacífico, un carácter de frontera militar que perduró hasta la década de 1660 en Cali, y en los de Toro y Santa Fe de Antioquia, hasta finales del siglo XVII. ${ }^{4}$ Este atributo coexistía con la formación de grandes

3. Hermann Trimborn, Señorío y barbarie en el Valle del Cauca. Estudio sobre la antigua civilización Quimbaya y grupos afines del oeste de Colombia (Cali: Universidad del Valle, 2005); Carlos Armando Rodríguez Ruiz, Tras las huellas del hombre prehispánico y su cultura en el Valle del Cauca (Cali: Instituto para la Investigación y la Preservación del Patrimonio Cultural y Natural del Valle del Cauca, 1992); Marcela Duque e Iván Darío Espinosa Peláez, "Historia y cultura de la población Nutabe en Antioquia" (Tesis de pregrado en Antropología, Universidad de Antioquia, 1994) 48-49.

4. Alonso Valencia Llano, Resistencia militar indígena en la gobernación de Popayán (Cali: Universidad delValle, 1991); Jorge Orlando Melo, "La conquista de Antioquia (1500-1580)", Historia de Antioquia, coord. Jorge Orlando Melo (Medellín: Suramericana de Seguros, 1987) 25-36; Juan David Montoya Guzmán y José Manuel González Jaramillo, Indios, poblamiento y trabajo en la provincia de Antioquia, siglos XVI y XVII (Medellín: Universidad Nacional de Colombia, sede Medellín, 2010) 154-156; Juan David Montoya Guzmán y José Manuel González Jaramillo, "Una sociedad en construcción: indios y españoles en la provincia de Antioquia", Visita a la provincia de Antioquia 
explotaciones agrícolas destinadas para el abastecimiento minero en el valle del río Cauca y, en Antioquia, con pequeñas y medianas propiedades rurales que no alcanzaban a abastecer las cuadrillas de esclavos en minas y aluviones de oro. ${ }^{5}$

Ambos fueron territorios intersticiales: la gobernación de Popayán entre las audiencias de Quito y Santa Fe fue una autarquía sustentada en fragmentos autónomos (ciudades) pero muy articulados entre sí, la cual aprovechaba estratégicamente el cruce de competencias de las dos audiencias y obispados. ${ }^{6}$ El valle era un espacio que conectaba a las llanuras del Pacífico con la meseta de Popayán, el valle del Patía y el Nuevo Reino de Granada, por lo que era una comarca comercial, ganadera y agricultora. Antioquia jurisdiccionalmente se desgajó de Popayán en 1569 y se consolidó en 1584. ${ }^{7}$ Su territorio fluctuó mucho: las villas de Guamocó y Ayapel se agregaron a la gobernación de Cartagena en el siglo XVIII y la de Arma se le añadió en 1756, así como la ciudad de Remedios posteriormente. Contaba con una autonomía interna respaldada por su minería, su guerra permanente contra los indios "de mala paz" hasta finales del siglo XVII y por la distancia de esos centros de poder político. ${ }^{8}$

A partir de mediados del siglo XVIII, empiezan a ser notorias las formas de ocupación del espacio hechas por los libres de todos los colores alrededor de capillas doctrineras y de haciendas, al margen de estas, en terrenos proindivisos y en cruces de caminos, de forma espontánea en el valle. ${ }^{9}$ En Antioquia ocurrió en selvas y despoblados, pero después de 1780, acciones que fueron direccionadas por los representantes de la monarquía, en el marco de las reformas borbónicas. ${ }^{10}$

por Francisco de Herrera Campuzano, 1614-1616 (Medellín: Universidad Nacional de Colombia, 2010) 11-35; Paola Andrea Berrío, La muerte de Andrés Valdivia, primer gobernador de Antioquia, 1569-1575 (Bogotá: Instituto Colombiano de Antropología e Historia, 2018).

5. Germán Colmenares, Cali: terratenientes, mineros y comerciantes, siglo XVIII (Bogotá:Tercer Mundo Editores / Universidad del Valle / Banco de la República / Colciencias, 1997); Alonso Valencia Llano, Indios, encomenderos y empresarios en el Valle del Cauca (Cali: Gobernación del Valle del Cauca, 1996) 43-89; Beatriz Patiño Millán, "La provincia de Antioquia en el siglo XVIII", Historia de Antioquia, coord. Jorge Orlando Melo (Medellín: Suramericana de Seguros, 1987) 63;Víctor Álvarez Morales, “La sociedad colonial, 1580-1720", Historia de Antioquia, coord. Jorge Orlando Melo (Medellín: Suramericana de Seguros, 1987) 27-28.

6. Marta Herrera Ángel, Popayán: la unidad de lo diverso. Territorio, población y poblamiento en la provincia de Popayán, siglo XVIII (Bogotá: Universidad de los Andes, 2009) 66-84, 171-175.

7. Montoya Guzmán y González Jaramillo, "Una sociedad” 16-18.

8. William Jaramillo Mejía, Antioquia bajo los Austrias, vol. 1 (Bogotá: Instituto Colombiano de Cultura Hispánica, 1996) 123-278; Ana Catalina Reyes Cárdenas y Juan David Montoya Guzmán, eds., Poblamiento y movilidad social en Colombia, siglos XVI-XX (Medellín: Universidad Nacional de Colombia, sede Medellín, 2007). En esta compilación se desarrolla a grandes rasgos esta caracterización anotada arriba.

9. Eduardo Mejía Prado, El origen del campesino vallecaucano. Siglos XVIII-XIX (Cali: Universidad del Valle, 1993).

10. Roberto Luis Jaramillo, "La colonización antioqueña", Historia de Antioquia, coord. Jorge Orlando Melo (Medellín: Suramericana de Seguros, 1987) 135-136. 
Estas características distintivas hacen parecer que una síntesis de los pueblos de indios en dichas regiones fuera la siguiente: más temprano en el valle (a mediados del XVI), y más tarde y continuamente en Antioquia (desde finales del XVI hasta mediados del XVII), se desestructuraron étnicamente las comunidades de raigambre prehispánica bajo la encomienda, las migraciones, las guerras, el comercio, la minería y las estancias, lo cual dio origen a colectividades heterogéneas que encontraron en lo hispánico y cristiano su articulación en el orden social. Con ello desaparecieron lenguas y prácticas rituales en favor de lo católico y lo español. De la misma manera, se cambiaron territorialidades ancestrales por las dadas en el contexto hispánico del pueblo de indios y las estancias, que eran formas de poblamiento más articuladas a los mercados y proyectos coloniales. Dicha hispanización generó varios contactos con libres, esclavos y las élites regionales, lo que hizo que muchos de los poblados indígenas fueran ocupados por individuos y familias de estas calidades sociales. Además, se produjeron procesos de mestizaje que diluyeron la presencia india en ambas regiones. Esta visión teleológica ha sido matizada en la última década por varios trabajos, ${ }^{11}$ pero predomina la imagen de unas comunidades indígenas subyugadas, pasivas e instrumentalizadas para el trabajo, la fe y los proyectos de las elites españolas que sirvieron de puente hacia el poblamiento de las castas y su incorporación —o resistencia— al orden planteado por las autoridades. ${ }^{12}$

\section{Una revisión bibliográfica sobre los indios de Antioquia y el valle del río Cauca}

La lectura de la bibliografia especializada sobre los indios puede dar cuenta de que las historias económicas, sociales y estructurales han predominado en la práctica historiográfica para el acercamiento a dichos colectivos y sus transformaciones. A lo largo de las tres últimas décadas de finales del siglo XX y las dos primeras

11. Berrío; Héctor Cuevas Arenas, Los indios en Cali, siglo XVIII (Cali: Universidad del Valle, 2012); Héctor Cuevas Arenas, "Aproximaciones a las expresiones discursivas sobre el orden social y político desde los indios: ejemplos de la provincia de Antioquia (1680-1720)" (Ponencia, XIX Congreso Colombiano de Historia, Asociación Colombiana de Historiadores, 2019); Héctor Cuevas Arenas, Tras el amparo del rey. Pueblos indios y cultura política en el valle del río Cauca, 16801810 (Quito / Bogotá: FLACSO, sede Ecuador / Universidad del Rosario, 2020); Héctor Cuevas Arenas y Andrés Felipe Castañeda Morales, "Un acercamiento a la configuración de los pueblos de indios de la provincia de Antioquia colonial”, Comunidades epistemológicas. Investigando la actualidad desde diversas perspectivas, t. 1, comps. María Eufemia Freire Tigreros y Diana Restrepo Rodríguez (Cali: Universidad Santiago de Cali, 2019) 131-154.

12. Alonso Valencia Llano, "Evolución de los pueblos de indios en el Valle del Cauca", Anuario de Historia Regional y de las Fronteras 2-3 (1998): 99-122; Mejía Prado; Wither Amalia SalazarVargas, "Resguardos en Antioquia: crisis y desintegración, 1750-1850" (Tesis de pregrado en Historia, Universidad de Antioquia, 1994); Duque y Espinosa Peláez; Luis Miguel Córdoba Ochoa, "Los mil forajidos de Antioquia y los mohanes de Ebéjico", Anuario Colombiano de Historia Social y de la Cultura 29 (2002): 7-44; Gregorio Saldarriaga, "La loma de los empalados y la tierra de nadie: frontera y guerra en la Provincia de Antioquia, 1540-1550”, Historia Crítica 49 (2013): 11-33, doi: 10.7440/histcrit49.2013.02. 
del XXI, hay estudios cuantitativos, ${ }^{13}$ investigaciones etnohistóricas con carácter cualitativo funcional-estructuralista ${ }^{14}$ y trabajos de síntesis socioeconómica. ${ }^{15}$ También existen textos que combinan las anteriores inquietudes con los aportes y los métodos de la antropología, con preguntas del orden de la etnogénesis, las territorialidades, las formas de gobierno locales junto a la redistribución o la explotación étnica y comunitaria de los recursos. ${ }^{16}$ Estas contribuciones, con los matices anotados, constituyen una etnohistoria desde la reconstrucción de la historia de las sociedades colonizadas por los europeos a partir de los cambios, las interacciones y articulaciones con la sociedad hegemónica, según la tipología ofrecida por Marco Curátola Petrocchi. ${ }^{17}$

Paralelamente, en especial desde la última década, ha aumentado el interés por fenómenos culturales, como el estudio de las identidades, del cambio cultural, de las transformaciones de las prácticas económicas, rituales y de sanación a partir de una concepción dialógica en medio de lo hispánico y de lo heredado de sociedades anteriores al contacto. ${ }^{18}$ En una dinámica parecida, combinada con el tema

13. Silvia Padilla Altamirano y otros, La encomienda en Popayán. Tres estudios (Sevilla: Escuela de Estudios Hispano-americanos / Consejo Superior de Investigaciones Científicas, 1977); Beatriz Patiño Millán, Criminalidad, ley penal y estructura social en la provincia de Antioquia, 1750-1820 (Medellín: IDEA, 1994); Beatriz Patiño Millán, Riqueza, pobreza y diferenciación social en la Provincia de Antioquia durante el siglo XVIII (Medellín: Universidad de Antioquia, 2011).

14. Friede; González Pacciotti;Valencia Llano, Resistencia; Luis Miguel Córdoba Ochoa, "Vivir como gitanos: los indios forasteros en la ciudad de Antioquia en el siglo XVII", Ameriña. Territorio Fluctuante 1.1 (2002): 24-29; Katerine Bolívar Acevedo, "Conflictos entre indios y mestizos por la posesión de tierras en la Provincia de Antioquia, 1756-1810" (Tesis de pregrado en Historia, Universidad Nacional de Colombia, sede Medellín, 2010);Víctor Zuluaga Gómez, Historia extensa de Pereira (Pereira: Universidad Tecnológica de Pereira, 2013); Víctor Zuluaga Gómez, Una historia pendiente. Indígenas desplazados en el Antiguo Caldas (Pereira: Gráficas Buda, 2006); Luis Javier Caicedo, "475 años de la entrada de los españoles al valle de Aburrá y 400 años de la fundación del pueblo de indios de San Lorenzo de Aburrá, origen de Medellín (1541-1616-2016)" (Documento inédito, 2014); Juan David Montoya Guzmán y César Augusto Lenis Ballesteros, Dos momentos del valle de Aburrá: entre lo hispánico y lo colonial (Medellín: Alcaldía de Medellín, 2017).

15. Salazar Vargas; Larry Vito Larrichio, La construcción multicultural de una economía colonial. Cambio demográfico y organización del trabajo en el Valle medio del Cauca siglo XVIII (Pereira: Universidad Tecnológica de Pereira, 2018).

16. Duque y Espinosa Peláez; Sofia Botero Páez, "De los hevexicos a los catíos en la provincia de Antioquia", Boletín de Antropología 18.35 (2004): 15-50; Carlos Mario Herrera Correa, "Narrativas y lógicas de una memoria mestiza", Boletín de Antropología 19.36 (2005): 33-60; Cuevas Arenas, Los indios en Cali; Héctor Cuevas Arenas, La república de indios: un acercamiento a las encomiendas, mitas, pueblos de indios y relaciones interestamentales en Cali, siglo XVII (Cali: Archivo Histórico de Cali, 2005); Montoya Guzmán y González Jaramillo, Indios, poblamiento y trabajo; Cuevas Arenas y Castañeda Morales, "Indios y encomenderos".

17. Marco Curátola Petrocchi, "Los cincos sentidos de la etnohistoria", Memoria Americana 20.1 (2012): 67-68.

18. Córdoba Ochoa, "Los mil forajidos"; Mauricio Alejandro Gómez Gómez, "Indios contra encomenderos en tierra de frontera. Antioquia a inicios del siglo XVII", Trashumante. Revista Americana de Historial Social 3 (2014): 8-26; Mauricio Alejandro Gómez Gómez, Del chontal al 
del acceso a la justicia, se sitúa un trabajo de Luis Miguel Córdoba Ochoa, donde ubica el impacto de lo español en las memorias étnicas. ${ }^{19}$ En otra vía, en una intersección entre historia, estudios políticos y la cultura política como proceso, que se expresa en discursos y prácticas, están los trabajos de Elizabeth Salgado y los de Héctor Cuevas Arenas. ${ }^{20}$ Los indígenas de estos espacios también han sido estudiados en investigaciones que se sitúan dentro de marcos más amplios, especialmente la Real Audiencia de Santafé, o en problemáticas más amplias, que explican lo indio en contextos más generales. ${ }^{21}$ Las migraciones de indios sonsones y armas, como los de Buga a Supía, en la ciudad de Anserma, ubicada en la cuenca media del río Cauca, y viceversa, son parte de los hechos abordados por Gloria Patricia Lopera Mesa. ${ }^{22}$

Las caracterizaciones de lo "indio" en la mayoría de los trabajos de corte socioeconómico de las décadas de 1970, 1980 y 1990 giran alrededor las continuidades culturales, sociales y políticas respecto a lo prehispánico, aunque no hubiera claridad respecto de lo que significaran o expresaran dichas diferencias. Solo se definieron por oposición a lo hispánico, sin tener muy en cuenta las transformaciones y etnogénesis dadas durante la conquista. ${ }^{23}$ Lo indígena se entendió así desde la pervivencia cultural y no tanto desde su capacidad de diálogo y adaptación. Esta visión sobre lo indio se ha orientado hacia una consideración generalmente reactiva o pasiva de la agencia indígena en la interacción con lo europeo, dando lugar a análisis victimizantes, aún en la década del $2000 .{ }^{24}$

ladino. Hispanización de los indios de Antioquia según la visita de Francisco de Herrera Campuzano, 1614-1616 (Medellín: Universidad de Antioquia, Fondo Editorial FCSH, 2015).

19. Luis Miguel Córdoba Ochoa, "La memoria del agravio en los indígenas según la visita de Herrera Campuzano a la gobernación de Antioquia (1614-1616)", Revista Historia y Justicia 3 (2014): 228-255, doi: $10.4000 /$ rhj.5677.

20. Elizabeth Karina Salgado Hernández, Comuneros indígenas en Antioquia. Los levantamientos en los pueblos de Buriticá y Sopetrán en 1781 (Bogotá: Instituto Colombiano de Antropología e Historia, 2015); Héctor Cuevas Arenas y Andrés Felipe Castañeda Morales, "Indios y encomenderos: acercamientos a la encomienda desde la cultura política y el pacto tributario.Valle del río Cauca, 1680-1750", Historelo. Revista de Historia Regional y Local 11.22 (2019): 165-197, doi: 10.15446/ historelo.v11n22.72344; Cuevas Arenas, "Aproximaciones”; Cuevas Arenas, Tras el amparo.

21. Margarita Garrido, Reclamos y representaciones. Variaciones sobre la política en el Nuevo Reino de Granada, 1770-1815 (Bogotá: Banco de la República, 1993); Herrera Ángel, Popayán; Nicolás Ceballos Bedoya, "Usos indígenas del Derecho en el Nuevo Reino de Granada. Resistencia y pluralismo jurídico en el derecho colonial, 1750-1810", Revista Estudios Socio-Jurídicos 13.2 (2011): 223-247; Gregorio Saldarriaga, "Trabajo y vida indígenas en los trapiches del Nuevo Reino de Granada, 1576-1674”, Anais do Museu Paulista: História e Cultura Material 25.1 (2017): 149-168.

22. Gloria Patricia Lopera Mesa, "Creando posesión vía desposesión.Visitas a la tierra y conformación de resguardos indígenas en la Vega de Supía, 1559-1759”, Fronteras de la Historia 25.2 (2020): 120-156, doi: 10.22380/20274688.819.

23. Una excepción de este panorama es libro de Jacques Aprile-Gniset, Notas sobre la fundación de Tulúa (Tulúa: Unidad Central del Valle del Cauca, 1985).

24. Córdoba Ochoa, "Vivir"; Cuevas Arenas, La república. 
Los trabajos hechos especialmente desde la Universidad de Antioquia y su carrera de Antropología han aportado una visión matizada de lo anterior respecto a la definición de lo indio colonial. Estas investigaciones han construido análisis etnohistóricos, que si bien definen lo indio por simple oposición a lo hispánico, también lo ubican desde la capacidad de negociación y adaptación para trasformar territorialidades, como organización social, política y cultural. ${ }^{25}$

Una ruptura también significativa la han desarrollado algunos trabajos desde lo social y económico en la década de 2010, al fijarse por cambios demográficos, laborales, de explotación de recursos, junto a los cambios en las identidades sociales, las adscripciones políticas y el procesamiento de los conflictos. ${ }^{26}$ Estos textos no abordan lo indio desde la continuidad, sino desde la ruptura con lo prehispánico y las etnicidades dinámicas resultantes de la conquista. Esta óptica otorga a los indígenas capacidad de agencia y negociación a partir de su papel subordinado. ${ }^{27}$

También lo indio ha sido abordado desde los diálogos con el poder político, la cultura política, las identidades y los discursos sobre el orden social. El primer trabajo específico ubicado en esta línea para Antioquia es el de Nicolás Ceballos Bedoya para el 2011, y en elValle, uno publicado en 2019 por Héctor Cuevas Arenas y Andrés Felipe Castañeda Morales. ${ }^{28}$ Desde esta tendencia, lo indio también se adapta y negocia con lo hispánico, al pasar de una categoría étnica y social a una que incorpora lo jurídico y político, que adquiere sentido en la alteridad, la subordinación, junto a los lenguajes y prácticas legales. Se orienta el interés investigativo hacia aspectos del pacto entre gobernantes y gobernados, las identidades que involucran intereses individuales y colectivos y la disputa jurídica como un campo social diferenciado.

Los pleitos por las tierras, los problemas con las autoridades, tributos y tributarios y la subordinación social y política, junto a dinámicas económicas, han constituido la mayor parte del acervo para llegar a lo indio colonial de estos espacios específicos con el predominio de enfoques económicos y sociales. Ha habido un énfasis en los procesos de dominación y resistencia armada, etnocidio, formas de trabajo e incorporación a mercados provinciales e imperiales. Sin embargo, de manera ascendente, los acercamientos desde la cultura política, el cambio cultural, la cotidianidad, la mediación y la negociación con los poderes locales y regionales, se están consolidando, sin olvidar los aportes de la historia socioeconómica y estructural.

\section{Duque y Espinosa Peláez; Botero Páez; Herrera Correa.}

26. Montoya Guzmán y González Jaramillo, Indios, poblamiento y trabajo; Montoya Guzmán y Lenis Ballesteros; Cuevas Arenas, Los indios; Gómez Gómez, "Indios contra encomenderos"; Córdoba Ochoa, "La memoria del agravio".

27. Aunque su problemática es diferente, los cambios culturales que afectan la vida cotidiana se encuentran en el trabajo de Gómez Gómez, Del chontal al ladino. Desde la resistencia armada, Saldarriaga ofrece una explicación en este sentido.Véase Saldarriaga, "La loma de los empalados".

28. Ceballos Bedoya; Cuevas Arenas y Castañeda Morales, "Indios y encomenderos". 
Lo "indio" ha sido definido de muchas maneras dentro de las prácticas historiográficas aquí revisadas. La mayoría de veces es una categoría social, económica y jurídica procesual, dada por el uso; en el enfoque socioeconómico, constituían sujetos de dominación y, por lo tanto, generaron acciones de resistencia desde lo legal o lo informal, en un proceso que a largo plazo significó la pérdida de sus costumbres y expresiones culturales distintivas. Los indios coloniales fueron actores nacidos de la ruptura de lo prehispánico y reestructurados para servir a lo hispánico. Del mismo modo, fueron la fuerza de trabajo que articuló regiones al proyecto económico imperial, a través de la mita y la encomienda, y de ahí, suscitaron transformaciones en la estructura del poblamiento y de la explotación agrícola o minera. La institucionalidad que se destinó a los indígenas fue un puente para el establecimiento de una sociedad mestiza y campesina en el siglo XVIII; desde la capilla doctrinera se articularon con vecinos pobres, esclavos y libres de todos los colores y, a partir del servicio personal, se estructuraron capitales para la compra de esclavos o el pago a personas libres.

Para los estudios de corte más etnohistórico y político producidos desde la década de 1990, como los realizados por Marcela Duque e Iván Espinosa Peláez; Juan David Montoya Guzmán y José Manuel González Jaramillo; Mauricio Alejandro Gómez Gómez; Héctor Cuevas Arenas; Paola Andrea Berrío, Cuevas Arenas y Castañeda Morales, lo indígena se caracteriza por la capacidad de negociación, adaptación, mediación y resistencia de formas heterogéneas con otros sectores, donde vivieron procesos de cambio en sus concepciones y prácticas hacia lo hispánico, sin consideraciones negativas sobre este proceso o una percepción de pérdida cultural. Estos aportes resaltan la creatividad política y cultural frente a los poderes locales y regionales. Respecto a lo indio, se observa la poca adopción del término "calidad social" que han asumido autores como Margarita Garrido, Max S. Hering Torres, Joanne Rappaport y Cuevas Arenas en alguno de sus trabajos. ${ }^{29}$

También las tendencias mencionadas destacan la capacidad de formar comunidades en entornos económicos desestructurantes, tales como la búsqueda de un sistema monetario en el pago del tributo, la existencia de estancias, minas y aluviones. El tributo, por ejemplo, fue un elemento para reclamar correspondencia entre los gobernantes y los gobernados, pero no como una reciprocidad andina o de raigambre prehispánica, sino en los términos de una sociedad hispánica colonial. La mayor conflictividad respecto a los tributos y la categorización que generaban, desde mediados del siglo XVIII, fue posiblemente por las transformaciones del pacto tributario y de sus mecanismos de cobro más lesivos hacia las colectividades.

Los textos reseñados como parte de la tendencia que se preocupa de la política, convergen con los de Ceballos Bedoya, Garrido y Marzahl respecto a la búsqueda de justicia de sectores subalternos, las consideraciones de lo justo e injusto en

29. Margarita Garrido, Libres de todos los colores en la sociedad colonial tardía. Discursos y prácticas (Cali: Universidad del Valle, 1995); Max S. Hering Torres, "Color, pureza, raza: la calidad de los sujetos coloniales", La cuestión colonial, ed. Heraclio Bonilla (Bogotá: Universidad Nacional de Colombia, 2011) 451-469; Cuevas Arenas, Tras el amparo 14. 
un mundo jerarquizado y lo segregado de la obediencia y el desacato. Para esta corriente de investigación, lo indio se define desde las prácticas, el conflicto y su lucha por el reconocimiento como individuos y colectivos articulados al orden político, representado por la justicia, el derecho y la lealtad al monarca, desde su condición de haber sido los primeros pobladores del territorio. También por su minoría política, pobreza, miseria y rusticidad. ${ }^{30}$

Las sociabilidades no han sido objetivo principal de las investigaciones para estas dos regiones, pero con la corriente cultural y política han ganado importancia y superado a las visiones generadas por las formas de trabajo y la articulación a mercados regionales. Sediciones y huidas (Ceballos Bedoya), discursos y reuniones ocultas (Salgado Hernández), faccionalismos ${ }^{31}$ y dinámicas horizontales y verticales del clientelismo son ejemplo de ello. ${ }^{32}$

La historiografia colonialista sobre estas regiones ha construido unos contextos de situaciones de dominación, resistencia y adaptación, ya sea desde la configuración de redes y acomodos informales, o a partir de la apelación a lo legal, pero vistos mayoritariamente en un proceso de dilución de lo prehispánico por las dinámicas del mercado, la hispanización y las guerras. Así, la agencia en la mayoría de los casos es de corte estructural y los repertorios para afrontar los conflictos se desplegaban en coyunturas tales como conflictos armados, afectaciones a las tierras comunales, implementaciones de tasas tributarias y asuntos criminales en torno a lo material del sometimiento. La evasión de las encomiendas y pueblos como acción política es también parte del abanico de posibilidades para enfrentar la autoridad, acudir a otros tribunales o escapar a los "espacios vacíos y $\sin$ ley" ${ }^{33} \mathrm{La}$ huida es un punto de conexión entre lo socioeconómico con lo cultural y político.

En los escritos que combinan lo cultural con lo político de la última década, la agencia india es vista de manera dialógica, donde el poder es considerado como un intercambio asimétrico de valoraciones, expectativas y de prácticas entre las autoridades de distinto nivel y los indios. También hay una consideración de "lo político" más allá de lo institucional o lo normativo que se lleva a los planos de contextos cotidianos afuera de los tribunales o la denuncia formal. De esta forma, la agencialidad india, si bien es subordinada, no es simplemente reactiva ni está absolutamente supeditada a las herramientas y nociones de los gobernantes, pues los indios y las comunidades involucradas fueron activos en la configuración de sus relaciones sociales y políticas, ya sea desde los discursos ocultos de James Scott ${ }^{34}$ como lo trabaja Salgado, o al apelar a la justicia de la Corona en el marco de un cuerpo político compuesto y atravesado por intereses, redes y conexiones

30. Garrido, Reclamos y representaciones 367-368; Ceballos Bedoya 227-231.

31. Cuevas Arenas, "Aproximaciones".

32. Cuevas Arenas, Tras el amparo 139-222.

33. Duque y Espinosa Peláez 141-142; Córdoba Ochoa, "Vivir como gitanos"; Córdoba Ochoa, "La memoria del agravio" 248-249; Córdoba Ochoa, "Los mil forajidos"; Botero Paéz 18; Ceballos Bedoya 225-227, 245; Caicedo 74-75.

34. James C. Scott, Los dominados y el arte de la resistencia. Discursos ocultos (México: Ediciones Era, 2000). 
de sus actores locales, regionales e imperiales. Aun afuera del marco ofrecido por la monarquía, como lo demuestran los trabajos de Berrío y Gregorio Saldarriaga con los indios de "mala paz" del norte del cañón del Cauca, algunos grupos en el último cuarto del siglo XVI establecieron alianzas con españoles, con cacicazgos sometidos y demás agentes según las dinámicas del juego político. La mediación y la negociación participaban de la configuración regional de la Corona con actores locales y, del mismo modo, eran parte de los repertorios destinados a la participación activa en la construcción de la hegemonía política, social y cultural que contextualiza el entendimiento de conflictos, necesidades y problemáticas.

Las autoridades locales indígenas son presentadas como intermediarias entre las comunidades con los curas, oficiales, encomenderos y vecinos, en un papel donde lo coercitivo se entreveraba con los intereses de los distintos agentes. Problemáticas del orden de las deudas por el cobro de tributo y la subordinación de los caciques locales a autoridades españolas son motivos comunes en la historiografia de corte estructural y socioeconómico. En la cultural y política, este panorama se vuelve más flexible con la interacción cotidiana y formal entre los agentes, los símbolos y los discursos y las prácticas de poder político local. Procesos como la crisis cacical en el siglo XVIII, que ha sido estudiada profusamente en los Andes, hacen más complejas las consideraciones sobre estos actores, al hacerlos participar más activamente en las estrategias y tácticas del poder en sus pueblos. ${ }^{35}$

\section{Tiempos y espacios}

Respecto a los periodos analizados, en los estudios sobre la conquista predomina la consolidación de la encomienda como instrumento efectivo de mano de obra (1536-1570), con la excepción de los textos de Cuevas Arenas, quien estudia los siglos XVII y XVIII en el valle del río Cauca, así como el enfoque de larga duración e historia ambiental que usa Luis Francisco López Cano, ${ }^{36}$ los trabajos que se ocupan de toda la colonia hechos por Víctor Zuluaga Gómez y el de Larry Vito Larrichio, o el estudio de Jacques Aprile-Gniset sobre las formas de poblamiento de Tuluá a finales del siglo XVII hasta mediados del XVIII. Para el espacio antioqueño, el interés se lo lleva también la conquista, la encomienda (ambas entre 1540 y 1616), el afianzamiento de los pueblos de indios y las visitas del oidor Herrera Campuzano a comienzos del XVII, motivado parcialmente por la transcripción de dicho ejercicio de poder regio realizada por Juan David Montoya Guzmán y José Manuel González Jaramillo. Otro eje temporal en Antioquia, pero con menor

35. Salgado Hernández; Héctor Cuevas Arenas, "De caciques hereditarios a alcaldes y mandones electos. Legitimidad del poder local en los pueblos de indios constituidos con una base étnica, en el valle del río Cauca (1675-1800)", Historelo. Revista de Historia Regional y Local 9.18 (2017): 14-48, doi: 10.15446/historelo.v9n18.61369.

36. Luis Francisco López Cano, Reconocimiento etnohistórico del municipio de Santiago de Cali. Siglos XVI-XIX (Cali: Instituto para la Investigación y la Preservación del Patrimonio Cultural y Natural del Valle del Cauca / Gobernación delValle del Cauca, 2008). 
cantidad de investigaciones, lo constituyen las reformas borbónicas, especialmente desde 1750 hasta el final del periodo colonial, como lo han desarrollado Margarita González Pacciotti, Wither Amalia SalazarVargas, Katerine Bolívar Acevedo y Elizabeth Karina Salgado Hernández.

Temporalmente en el valle, el periodo desde 1570 hasta 1620 no ha sido abordado sistemáticamente. En Antioquia, el tiempo después de la fundación de algunos pueblos de indios (1616), hasta la llegada de reformas borbónicas (década de 1750) no se ha explorado por la historiografia antioqueña, con excepción de una ponencia. ${ }^{37}$ A pesar de existir documentos como la visita de 1670-1671 hecha para la ciudad de Antioquia por Francisco de Montoya y Salazar y los fondos documentales de archivos coloniales, esta fase intersticial no ha llamado mucho el interés de los investigadores.

Índices, estadísticas y tendencias han sido parte del lenguaje predominante en el acercamiento a lo indio en estas regiones, al lado de formas laborales, encomiendas, el desarrollo de políticas de traslado, el legalismo, la coexistencia conflictiva o positiva de indios con libres y la separación o connivencia de estos sectores entorno a la iglesia local,junto a la explotación de las gentes y los recursos. Sin embargo, respecto a los traslados, se configura una diferencia entre el espacio antioqueño y el del valle, puesto que, en la década de 1750, y ocasionalmente en las siguientes, hubo varios intentos de fusión y de extinción de varios pueblos de indios en la gobernación de Antioquia. Afortunadamente para los indios, no se hizo ninguna mudanza y por ello surgieron otras posibles soluciones desde los distintos agentes de la Corona, como la de eliminar el tributo y repartir las tierras a sus habitantes, que planteó el gobernador Francisco Silvestre en $1785 .{ }^{38}$ Esto ha sido explicado por la diferencia de actividades económicas o por la capacidad de resistencia frente a los poderes estatales. ${ }^{39}$ En el caso del valle del río Cauca, aun con menor población indígena, parece que esos intentos de reformas y sus alcances no fueron comparables al caso antioqueño. De hecho, se sostiene que no hubo mayores innovaciones en la administración de las tierras de indios en el valle, ni fructificaron las tentativas de la Corona o de los vecinos para extinguir pueblos de indios. ${ }^{40}$

El ámbito espacial en los diversos trabajos revisados ha sido preferentemente regional, ya sea por el gran tamaño de las jurisdicciones de ciudades coloniales, ${ }^{41}$ o, lo más común en el caso antioqueño, el dado por las fuentes, como la visita de Herrera Campuzano a los pueblos del cañón del río Cauca y de la ciudad de Cáceres para los textos que trabajan los siglos XVI y XVII, o donde hubo rebeliones y conflictos en la segunda mitad el siglo XVIII, en los casos de Buriticá, Sopetrán

37. Cuevas Arenas, "Aproximaciones".

38. Patiño Millán, "La provincia" 66.

39. Patiño Millán, Riqueza 129-131.

40. Cuevas Arenas, Los indios; Cuevas Arenas, Tras el amparo.

41. Patiño Millán, Criminalidad; Zuluaga Gómez; Cuevas Arenas, La república; Cuevas Arenas, Los indios. 
y Sabanalarga, pueblos de dicho cañón, analizados por Bolívar o Salgado. Solo los aportes de Beatriz Patiño Millán, Cuevas Arenas y Castañeda Morales estudian el conjunto de dicha gobernación. Los procesos estudiados por Duque y Espinosa Peláez, Botero Páez, Saldarriaga y Zuluaga Gómez van más allá de la jurisdicción de una ciudad colonial, pero menos que la totalidad de la gobernación, ya que siguen las migraciones de los naturales, ya fuera por las huidas, por consenso con encomenderos o autoridades, o simplemente por voluntad propia. Algo parecido ocurre con los aportes de Alonso Valencia Llano y Cuevas Arenas, quienes escogieron espacialidades morfológicamente homogéneas (específicamente el valle del río Cauca) y con base en las cualidades de los grupos indígenas que los habitaban.

Más que por problemas concretos, parece que la elección de espacios es por la cantidad de información que se concentra en los archivos coloniales de cada jurisdicción y su procesamiento por unidades manejables, como, por ejemplo, los pueblos de indios. No ha habido estudios comparativos como tales entre estas y otras regiones, pero son comunes las alusiones a otras áreas, incluso en los imperiales, como el de la conquista trabajado por Saldarriaga. El trabajo de Berrío escapa a dichas generalizaciones, al usar un abordaje microhistórico y relacional en torno a la figura de Andrés de Valdivia y su muerte por grupos parcialmente incorporados a la monarquía.

\section{Conceptualizaciones}

Las conceptualizaciones usadas son variopintas: sus principales fuentes han sido la historia social británica, el marxismo, la historiografía económica, la segunda y tercera generación de Annales (Braudel y el primer LeRoy Ladurie, historia serial y demografia histórica). En la producción sobre Antioquia a comienzos del siglo XVII, ha habido un diálogo fructífero con los aportes conceptuales del evolucionismo cultural, el estructuralismo y la antropología económica. También ha existido una situación parecida con la arqueología regional en la búsqueda de elementos para establecer tipologías y fases de cambios colectivos y culturales.

Los trabajos etnohistóricos de Hermann Trimborn, John V. Murra y Frank Salomon han sido referentes para ambos espacios en cuestiones como la microverticalidad y el establecimiento de tipologías societales. ${ }^{42}$ Siguiendo con los enfoques conceptuales y problemas, destaca el uso de la sociología penal, estructural-materialista y cuantitativa que desarrolló Patiño Millán en sus libros junto al análisis de los debates al interior de las autoridades de la gobernación de Antioquia trabajado por González Pacciotti. De la misma forma, se considera aparte la orientación etnohistórica de mapeo y sistematización de datos escritos con la climatología que implementa López Cano para establecer periodizaciones en la ocupación de los

42. Trimborn; John V. Murra, Formaciones económicas y políticas del mundo andino (Lima: Instituto de Estudios Peruanos, 1975); Frank Salomon, Los señores étnicos de Quito en la época de los Incas (Otavalo: Instituto Otavaleño de Antropología, 1980). 
suelos y la presión hacia los pueblos de indios, ${ }^{43}$ la búsqueda de continuidades prehispánicas e indias coloniales planteadas por Duque y Espinosa Peláez, así como en el artículo de Herrera Correa y el de los "Los mil forajidos de Antioquia” de Córdoba Ochoa. Destaca también el examen de fuentes desde una óptica estructural con consideraciones etnográficas en los trabajos de Montoya Guzmán y González Jaramillo. Además, es notorio el abordaje de la historia social del derecho, junto al de las prácticas y la cultura política que desarrolla Nicolás Ceballos Bedoya en el artículo citado, aplicado a ejemplos antioqueños, que constituye parte de un marco espacial más amplio dado por el virreinato. En una línea parecida, complementada por un diálogo con la historia conceptual y la cultura política, están algunos textos de Cuevas Arenas a partir de lo lingüístico y lo extralingüístico. ${ }^{44}$

En la práctica historiográfica y etnohistórica se pueden apreciar la apropiación intelectual y los diálogos que se han establecido desde las universidades de Cali y Medellín, como la del Valle, la de Antioquia y la sede de la Universidad Nacional de Colombia, con el conocimiento producido en otros espacios, con lo que se ha legitimado la academia regional, al replantear narrativas generalizantes y nacionales sobre los indios y ubicarlos en espacios regionales concretos. Con ello, profundizaron el diálogo respecto a la relación de la nación con sus regiones. La plurietnicidad y el reconocimiento político de las comunidades ancestrales y étnicas fueron unos de los principales contextos en las dos últimas décadas del siglo XX para estos ejercicios académicos. También han hecho un contrapeso a la abundante presencia muisca y el altiplano cundiboyacense en la historiografia colonial.

Los enfoques estructurales y socioeconómicos se insertaban en discusiones más generales sobre las razones históricas de la discriminación y la subordinación social de indígenas y afros, del mestizaje como elemento identitario y distintivo de la nación colombiana, además de los debates más académicos sobre la articulación de las regiones a los mercados imperiales y su papel en el capitalismo de la Edad Moderna. Por eso, las relaciones laborales y de explotación marcaron en su momento la agenda investigativa.

Para los enfoques culturales y políticos, los entornos sociales y académicos se relacionan más con los marcos ofrecidos por el multiculturalismo y la interculturalidad, así como con el énfasis en las posibilidades de la antropología interpretativa y la agencialidad individual en lo colectivo. La cultura y la política no son marcos justificativos de explotación, sino de interacción, de creatividad y mediación asimétrica que crean y recrean a las comunidades e identidades.

\section{El marco dado por la monarquía}

La monarquía, como cuerpo político que atravesaba y legitimaba las relaciones sociales y políticas, es una idea (a excepción de Garrido, Herrera, Ceballos Bedoya,

43. López Cano.

44. Cuevas Arenas, "Aproximaciones”; Cuevas Arenas, Tras el amparo. 
Berrío, y un texto de Cuevas Arenas) ${ }^{45}$ que no ha sido tan complejizada. Esto, debido a la naturaleza de las preguntas económicas y sociales que generalmente han usado los diversos investigadores sobre el tema, junto a enfoques descriptivos de la dominación política en la mayoría de los casos.Vista de esta forma, la monarquía es considerada un entramado de poderes locales y regionales que atraviesan el aparato y el proyecto imperial institucional; es un agente para la explotación a los indios en pro de lo minero y en beneficio de los encomenderos, o un espacio contingente de negociación entre varios poderes ${ }^{46}$ y generalmente está acompañada de curas doctrineros. Así, el cuerpo político y social se ha entendido como garante de privilegios, ya fueran mercedes laborales hacia vecinos y encomenderos o de usufructo de las tierras de los indios. La historiografia resalta la presencia de la Corona a través de las visitas de la tierra, ya sea con el objetivo de explicitar un orden paternalista, pero cruzada por los intereses de los encomenderos o como arma de los indios para hacer denuncias sobre abusos.

Sin embargo, en la bibliografia que cruza lo histórico con lo cultural y político, la monarquía es una guardiana del orden social, dispensadora de justicia y de privilegios que, en su legitimación, debía negociar y salvaguardar los intereses y las jerarquías sociales locales. Por ello, para los indios operaba la noción de pacto tributario o de vasallaje, que es dialógico, contextualizado y de carácter regional, y que se ha trabajado en espacios más centrados en el imperio español, como, por ejemplo, los de Tristan Platt y Brian P. Owensby. ${ }^{47}$

En el caso general neogranadino, dicho pacto ha sido trabajado por Garrido ${ }^{48}$ y por Ceballos. La relación de los indios con la Corona en la cultura política y el derecho se considera en doble sentido: los indios existen desde su sumisión diferenciada y la construcción de hegemonía política y cultural, la cual era avalada y mediada por los discursos y las prácticas reguladoras de la Corona católica y universal española, junto a la Iglesia y sus agentes locales. Las demandas de los indios y las acciones de justicia de los oficiales y jueces reales retroalimentaban al cuerpo político y social. Lo mismo se explica respecto a las nociones y expectativas alrededor de la justica y la lealtad, que servían de vínculos sociales y de cultura política. Todo esto, en el marco de estrategias jurídicas y políticas que se entreveraban con la religión y la justicia redistributiva, que cruzaban a los actores y sus conflictos concretos, junto al conocimiento de los procedimientos de los tribunales y al cambio de razones de gobierno. A partir de estos aportes, parten las investigaciones de Cuevas Arenas y de Salgado en el terreno de la cultura política.

45. Cuevas Arenas, Tras el amparo.

46. Con unos intereses distintos — el de hacer una prosopografia y descripción de las élites antioqueñas en el siglo XVI y comienzos del siguiente-, Jaramillo Mejía aborda este problema, y de ahí, la articulación de lo indio a las encomiendas y privilegios de los encomenderos.

47. Tristan Platt, Estado boliviano y ayllu andino. Tierra y tributo en el norte de Potosí (Lima: Instituto de Estudios Peruanos, 1982); Brian P. Owensby, Empire of Law and Indian Justice in Colonial Mexico (Stanford: Stanford University Press, 2008).

48. Garrido, Reclamos y representaciones 135, 241, 236-266. 
La reflexión sobre la monarquía como cuerpo político e instancia institucional en la historiografia respecto al occidente neogranadino generalmente no ha acompañado al estudio de las sociedades indias del periodo colonial, con las debidas excepciones de Salgado y Cuevas Arenas. ${ }^{49}$ Esto se ha hecho sistemáticamente para ciudades vecinas y espacios más amplios, como, por ejemplo, lo desarrolló Marzahl para Popayán y su provincia, ${ }^{50}$ o los trabajos de Herrera Ángel que se han ubicado en la misma línea de otros lugares del virreinato. ${ }^{51}$ En dichos estudios, la monarquía articula o desarticula lo prehispánico en una dialéctica con el proyecto político y económico imperial, junto a la acción de las instancias informales del poder.

\section{Conclusiones}

Una revisión de los trabajos sobre los indios de los valles y montañas del actual occidente colombiano muestra un panorama en donde los temas y los problemas de una exploración social y cultural de la política están consolidándose como tendencia en los últimos años. Exploraciones respecto a la encomienda, las rebeliones, el acceso a la justicia, los tributos y el papel de los actores locales se han considerado de una manera más compleja que la antinomia de la dominación-resistencia, al involucrar la mediación y la negociación, así fuera asimétrica, entre gobernantes y gobernados. Los cambios en las preguntas investigativas muestran que la historia regional en estos casos participa de los grandes cambios epistemológicos y metodológicos de las ciencias sociales y humanidades, pero todavía está en consolidación lo cultural y lo político frente a las anteriores tradiciones académicas. Esto también da cuenta de la interdisciplinariedad que suscita el tema y la retroalimentación de conceptualizaciones que se historizan.

El interés de buscar pervivencias de lo prehispánico, de las prácticas de sometimiento y la integración a mercados imperiales todavía tiene un peso significativo en la práctica historiográfica respecto a los indígenas, pero poco a poco está dando paso a dinámicas flexibles y contextualizadas sobre la política, los conflictos y los cambios culturales sin esencialismos. Más allá de la consideración sobre un "Estado" donde solo había diálogo entre las elites blancas y la burocracia del rey en torno a los sometidos, ya se ha incorporado a los indios como agentes que actuaban desde los pleitos judiciales en el entendimiento de una monarquía compuesta donde las denuncias daban espacio a lo político y a la construcción de hegemonía. En este sentido, plantea Caroline Cunill que la negociación de los indios era más activa de lo que inicialmente se creía, al ayudar en la generación de discursos y prácticas coloniales a partir de lo contencioso y las disputas por los derechos de

49. Cuevas Arenas, Tras el amparo.

50. Peter Marzahl, Una ciudad en el Imperio. El gobierno, la política y la sociedad de Popayán en el siglo XVII (Popayán: Universidad del Cauca, 2013) 219-222.

51. Véase Marta Herrera Ángel, Ordenar para controlar. Ordenamiento espacial y control político en las llanuras del Caribe y en los Andes centrales neogranadinos, siglo XVIII (Bogotá:Academia Colombiana de Historia / Instituto Colombiano de Antropología e Historia, 2002); Herrera Ángel, Popayán. 
comunidades e individuos. ${ }^{52}$ En una dinámica parecida, se encuentra la opinión de Adrian Masters, en la cual el imperio también respondía de "abajo hacia arriba" en su configuración. ${ }^{53}$

Posiblemente la inexistencia de un marco cultural "común" prehispánico y la poca cantidad de indios respecto de los otros espacios de la monarquía hacen que cada estudio se centre en su región y que no haya mayor labor de síntesis y mucho menos de comparación. Sin embargo, hay puntos comunes, especialmente el cambio de lo étnico a lo genérico de lo indio colonial, las transformaciones sufridas por los traslados y el funcionamiento de las encomiendas en regiones intermedias y fronterizas. Afortunadamente, lo indio colonial sigue siendo un campo donde hay más preguntas que respuestas, ya que hay periodos como el siglo XVII que no han sido sistemáticamente abordados, y no hay trabajos sobre la historia ambiental (excepto el de Luis Francisco López Cano). ${ }^{54}$ Tampoco hay mayor abordaje desde los estudios de género o de historia de las mujeres. Todavía hace falta comprender las dinámicas de mutación, principalmente en el valle del río Cauca, entre las etapas Habsburgo y Borbón, para no simplificar esto en una relación de oposición. Lo simbólico de los discursos políticos también es un campo para explorar, así como lo ritual y la religiosidad. Las interacciones y conexiones entre los indios incorporados a la monarquía y los que no lo estaban igualmente son aspectos promisorios, así como los lazos entre los indígenas de diversas gobernaciones.

En fin, los aspectos por explorar son reflejo de la vitalidad de lo indio como tema de estudio, aun en regiones con poca presencia demográfica, pero sí social, cultural y política. Lo indio es una categoría que necesita seguir siendo explorada a partir de lo contextualizado en espacios y tiempos, y más en la historiografia colombiana, donde se ha subsumido en el mestizaje, especialmente en los siglos XVII y XVIII. La desnaturalización de la dominación, de las expresiones culturales, de los discursos y de las prácticas culturales y políticas aporta a la comprensión de estos actores y permite entender dinámicas de las afectaciones en el periodo republicano y sus interacciones con el Estado nacional. Esto aún afecta algunos procesos, como, por ejemplo, la exclusión social y la visibilización de lo étnico y campesino en el escenario colombiano y latinoamericano.

\section{Bibliografía}

Álvarez Morales, Víctor. “La sociedad colonial, 1580-1720”. Historia de Antioquia. Coord. Jorge Orlando Melo. Medellín: Suramericana de Seguros, 1987. Aprile-Gniset, Jacques. Notas sobre la fundación de Tulúa.Tulúa: UCEVA, 1985.

52. Caroline Cunill,"La negociación indígena en el Imperio ibérico:aportes a su discusión metodológica”, Colonial Latin American Review 21.3 (2012):391-412, doi: 10.1080/10609164.2012.730664.

53. Adrian Masters, "A Thousand Invisible Architects:Vassals, the Petition and Response System, and the Creation of Spanish Imperial Caste Legislation", Hispanic American Historical Review 98.3 (2018): 377-406, doi: 10.1215/00182168-6933534.

54. López Cano. 
Berrío, Paola Andrea. La muerte de Andrés Valdivia, primer gobernador de Antioquia, 15691575. Bogotá: Instituto Colombiano de Antropología e Historia, 2018.

Bolívar Acevedo, Katerine. "Conflictos entre indios y mestizos por la posesión de tierras en la Provincia de Antioquia, 1756-1810". Tesis de pregrado en Historia, Universidad Nacional de Colombia, sede Medellín, 2010.

Botero Páez, Sofía. "De los hevexicos a los catíos en la provincia de Antioquia”. Boletín de Antropología 18.35 (2004): 15-50.

Caicedo, Luis Javier. 475 años de la entrada de los españoles al valle de Aburrá y 400 años de la fundación del pueblo de indios de San Lorenzo de Aburrá, origen de Medellín (1541-1616-2016). Documento inédito, 2014.

Ceballos Bedoya, Nicolás. "Usos indígenas del Derecho en el Nuevo Reino de Granada. Resistencia y pluralismo jurídico en el derecho colonial, 17501810”. Revista Estudios Socio-Jurídicos 13.2 (2011): 223-247.

Colmenares, Germán. Cali: terratenientes, mineros y comerciantes, siglo XVIII. Bogotá: Tercer Mundo Editores / Universidad delValle / Banco de la República / Colciencias, 1997.

Córdoba Ochoa, Luis Miguel. "La memoria del agravio en los indígenas según la visita de Herrera Campuzano a la gobernación de Antioquia (1614-1616)”. Revista Historia y Justicia 3 (2014): 228-255. Doi: 10.4000/rhj.5677. "Los mil forajidos de Antioquia y los mohanes de Ebéjico". Anuario Colombiano de Historia Social y de la Cultura 29 (2002): 7-44.

."Vivir como gitanos: los indios forasteros en la ciudad de Antioquia en el siglo XVII” Ameriña. Territorio Fluctuante 1.1 (2002): 24-29.

Cuevas Arenas, Héctor y Andrés Felipe Castañeda Morales. "Indios y encomenderos: acercamientos a la encomienda desde la cultura política y el pacto tributario.Valle del río Cauca, 1680-1750”. Historelo. Revista de Historia Regional y Local 11.22 (2019): 165-197. Doi: 10.15446/historelo.v11n22.72344.

. "Un acercamiento a la configuración de los pueblos de indios de la Provincia de Antioquia colonial”. Comunidades epistemológicas. Investigando la actualidad desde diversas perspectivas. Tomo 1. Comps. María Eufemia Freire Tigreros y Diana Restrepo. Cali: Universidad Santiago de Cali, 2019.

Cuevas Arenas, Héctor. "Aproximaciones a las expresiones discursivas sobre el orden social y político desde los indios: ejemplos de la provincia de Antioquia (1680-1720)". Ponencia, XIX Congreso Colombiano de Historia, Asociación Colombiana de Historiadores, 2019.

. "De caciques hereditarios a alcaldes y mandones electos. Legitimidad del poder local en los pueblos de indios constituidos con una base étnica, en el valle del río Cauca (1675-1800)". Historelo. Revista de Historia Regional y Local 9.18 (2017): 14-48. Doi: 10.15446/historelo.v9n18.61369.

La república de indios: un acercamiento a las encomiendas, mitas, pueblos de indios y relaciones interestamentales en Cali, siglo XVII. Cali:Archivo Histórico de Cali, 2005.

. Los indios en Cali, siglo XVIII. Cali: Universidad del Valle, 2012. 
. Tras el amparo del rey. Pueblos indios y cultura política en el valle del río Cauca, 1680-1810. Quito / Bogotá: FLACSO, sede Ecuador / Universidad del Rosario, 2020.

Cunill, Caroline. "La negociación indígena en el Imperio ibérico: aportes a su discusión metodológica”. Colonial Latin American Review 21.3 (2012): 391-412. Doi: 10.1080/10609164.2012.730664.

Curátola Petrocchi, Marco. "Los cincos sentidos de la etnohistoria”. Memoria Americana 20.1 (2012): 35-181.

Duque, Marcela e Iván Espinosa Peláez. "Historia y cultura de la población Nutabe en Antioquia”. Tesis de pregrado en Antropología, Universidad de Antioquia, 1994.

Friede, Juan. Los quimbayas bajo la dominación española. Estudio documental 15391810. Bogotá: Carlos Valencia Editores, 1978.

Garrido, Margarita. Libres de todos los colores en la sociedad colonial tardía. Discursos y prácticas. Cali: Universidad del Valle, 1995.

. Reclamos y representaciones. Variaciones sobre la política en el Nuevo Reino de Granada, 1770-1815. Bogotá: Banco de la República, 1993.

Gómez Gómez, Mauricio. Del chontal al ladino. Hispanización de los indios de Antioquia según la visita de Francisco de Herrera Campuzano, 1614-1616. Medellín: Universidad de Antioquia, Fondo Editorial FCSH, 2015.

. "Indios contra encomenderos en tierra de frontera. Antioquia a inicios del siglo XVII". Trashumante. Revista Americana de Historial Social 3 (2014): 8-26.

González Pacciotti, Margarita. "El resguardo minero de Antioquia”. Anuario Colombiano de Historia Social y de la Cultura 9 (1979): 17-37.

Hering Torres, Max S. “Color, pureza, raza: la calidad de los sujetos coloniales”. La cuestión colonial. Ed. Heraclio Bonilla. Bogotá: Universidad Nacional de Colombia, 2011.

Herrera Ángel, Marta. Ordenar para controlar. Ordenamiento espacial y control político en las llanuras del Caribe y en los Andes centrales neogranadinos, siglo XVIII. Bogotá: Academia Colombiana de Historia / Instituto Colombiano de Antropología e Historia, 2002.

. Popayán: la unidad de lo diverso. Territorio, población y poblamiento en la provincia de Popayán, siglo XVIII. Bogotá: Universidad de los Andes, 2009.

Herrera Correa, Carlos Mario. "Narrativas y lógicas de una memoria mestiza". Boletín de Antropología 19.36 (2005): 33-60.

Jaramillo, Roberto Luis. "La colonización antioqueña”. Historia de Antioquia. Coord. Jorge Orlando Melo. Medellín: Suramericana de Seguros, 1987.

Jaramillo Mejía, William. Antioquia bajo los Austrias. Volumen 1. Bogotá: Instituto Colombiano de Cultura Hispánica, 1996.

Larrichio, Larry Vito. La construcción multicultural de una economía colonial. Cambio demográfico y organización del trabajo en el Valle medio del Cauca siglo XVIII. Pereira: Universidad Tecnológica de Pereira, 2018. 
Lopera Mesa, Gloria. “Creando posesión vía desposesión.Visitas a la tierra y conformación de resguardos indígenas en la Vega de Supía, 1559-1759”. Fronteras de la Historia 25.2 (2020): 120-156. Doi: 10.22380/20274688.819.

López Cano, Luis Francisco. Reconocimiento etnohistórico del municipio de Santiago de Cali. Siglos XVI-XIX. Cali: Instituto para la Investigación y la Preservación del Patrimonio Cultural y Natural delValle del Cauca / Gobernación del Valle del Cauca.

Marzahl, Peter. Una ciudad en el Imperio. El gobierno, la política y la sociedad de Popayán en el siglo XVII. Popayán: Universidad del Cauca, 2013.

Masters, Adrian. "A Thousand Invisible Architects:Vassals, the Petition and Response System, and the Creation of Spanish Imperial Caste Legislation”. Hispanic American Historical Review 98.3 (2018):377-406. Doi: 10.1215/001821686933534.

Mejía Prado, Eduardo. El origen del campesino vallecaucano. Siglos XVIII-XIX. Cali: Universidad del Valle, 1993.

Melo, Jorge Orlando. "La conquista de Antioquia (1500-1580)". Historia de Antioquia. Coord. Jorge Orlando Melo. Medellín: Suramericana de Seguros, 1987.

Montoya Guzmán, Juan David y César Augusto Lenis Ballesteros. Dos momentos del valle de Aburrá: entre lo hispánico y lo colonial. Medellín: Alcaldía de Medellín, 2017.

Montoya, Juan David y José Manuel González Jaramillo. Indios, poblamiento y trabajo en la provincia de Antioquia, siglos XVI y XVII. Medellín: Universidad Nacional de Colombia, sede Medellín, 2010.

. "Una sociedad en construcción: indios y españoles en la provincia de Antioquia". Visita a la provincia de Antioquia por Francisco de Herrera Campuzano, 1614-1616. Medellín: Universidad Nacional de Colombia, 2010.

Murra, John V. Formaciones económicas y políticas del mundo andino. Lima: Instituto de Estudios Peruanos, 1975.

Owensby, Brian P. Empire of Law and Indian Justice in Colonial Mexico. Stanford: Stanford University Press, 2008.

Padilla Altamirano, Silvia y otros. La encomienda en Popayán. Tres estudios. Sevilla: Escuela de Estudios Hispano-americanos / Consejo Superior de Investigaciones Científicas, 1977.

Patiño Millán, Beatriz. Criminalidad, ley penal y estructura social en la provincia de Antioquia, 1750-1820. Medellín: IDEA, 1994.

. "La provincia de Antioquia en el siglo XVIII". Historia de Antioquia. Coord. Jorge Orlando Melo. Medellín: Suramericana de Seguros, 1987. . Riqueza, pobreza y diferenciación social en la Provincia de Antioquia durante el siglo XVIII. Medellín: Universidad de Antioquia, 2011.

Platt, Tristan. Estado boliviano y ayllu andino. Tierra y tributo en el norte de Potosí. Lima: Instituto de Estudios Peruanos, 1982.

Rappaport, Joanne. El mestizo evanescente. Configuración de la diferencia en el Nuevo Reino de Granada. Bogotá: Editorial Universidad del Rosario, 2018. 
Reyes Cárdenas, Ana Catalina y Juan David Montoya Guzmán. Eds. Poblamiento y movilidad social en Colombia, siglos XVI-XX. Medellín: Universidad Nacional de Colombia, sede Medellín, 2007.

Rodríguez Ruiz, Carlos Armando. Tras las huellas del hombre prehispánico y su cultura en el Valle del Cauca. Cali: Instituto para la Investigación y la Preservación del Patrimonio Cultural y Natural del Valle del Cauca, 1992.

Salazar Vargas, Wither Amalia. "Resguardos en Antioquia: crisis y desintegración, 1750-1850”. Tesis pregrado en Historia, Universidad de Antioquia, 1994.

Saldarriaga, Gregorio. "La loma de los empalados y la tierra de nadie: frontera y guerra en la Provincia de Antioquia, 1540-1550”. Historia Crítica 49 (2013): 11-33. Doi: 10.7440/histcrit49.2013.02.

. "Trabajo y vida indígenas en los trapiches del Nuevo Reino de Granada, 1576-1674”. Anais do Museu Paulista: História e Cultura Material 25.1 (2017): 149-168.

Salgado Hernández, Elizabeth Karina. Comuneros indígenas en Antioquia. Los levantamientos en los pueblos de Buriticá y Sopetrán en 1781. Bogotá: Instituto Colombiano de Antropología e Historia, 2015.

Salomon, Frank. Los señores étnicos de Quito en la época de los Incas. Otavalo: Instituto Otavaleño de Antropología, 1980.

Scott, James C. Los dominados y el arte de la resistencia. Discursos ocultos. México: Ediciones Era, 2000.

Trimborn, Hermann. Señorío y barbarie en el Valle del Cauca. Estudio sobre la antigua civilización Quimbaya y grupos afines del oeste de Colombia. Cali: Universidad del Valle, 2005.

Valencia Llano, Alonso. "Evolución de los pueblos de indios en elValle del Cauca". Anuario de Historia Regional y de las Fronteras 2-3 (1998): 99-122.

. Indios, encomenderos y empresarios en el Valle del Cauca. Cali: Gobernación del Valle del Cauca, 1996.

- Resistencia militar indígena en la gobernación de Popayán. Cali: Universidad del Valle, 1991.

Zuluaga Gómez,Víctor. Historia extensa de Pereira. Pereira: Universidad Tecnológica de Pereira, 2013.

. Una historia pendiente. Indígenas desplazados en el Antiguo Caldas. Pereira: Gráficas Buda, 2006. 